\title{
What is the cut-off level for commercial kits for antithyroperoxydase antibody
}

Dan Perețianu ${ }^{1}$, Mara Carşote ${ }^{2}$, Mihaela Ratcu ${ }^{1}$, Payman Gharibafshar ${ }^{1}$, Bogdan Oprişan ${ }^{1}$, Cristina Daniela Staicu ${ }^{1}$,

Institute of Endocrinology, 2. Medical Center "Povernei" -

Bucureşti/Bucharest; Romania/Roumanie

Aim.

The biological diagnostic of Hashimoto thyroiditis (HT) is based on higher than normal levels of antithyroperoxydase antibodies (ATPO). Our goal was to establish the cut-off limit of normality (the upper limit) for ATPO - in our thyroid normal patients. This limit and not that of the laboratory should be used as diagnosis of Hashimoto thyroiditis.

\section{Material\&Method.}

1. ATPO was investigated in patients with normal level of thyroid hormones (euthyroidism) and normal ultrasound of thyroid (linear probe at 7,5-10 MHz).

2. ATPO was analyzed in several Bucharest laboratories, accredited for this investigation. The laboratory cut-off limit for normality was $34 \mathrm{ui} / \mathrm{ml}$.

3. Conventionally, the normality is considered as the average (mean) plus/minus standard deviation multiply by 2 .

\section{Results.}

A. Patients: total 268; women, 227, men, 41 , age, average, 45,87 years, median, 44 years; average TSH, $1,8 \mathrm{mui} / \mathrm{ml}, \mathrm{FT} 4,15,6 \mathrm{nmol} / \mathrm{l}$.

B. ATPO level was: average: 8,65 ui/ml, standard deviation: 7,22. Therefore, the upper limit/cut- off for ATPO level should be 23,08 ui/ml

\section{Discussion.}

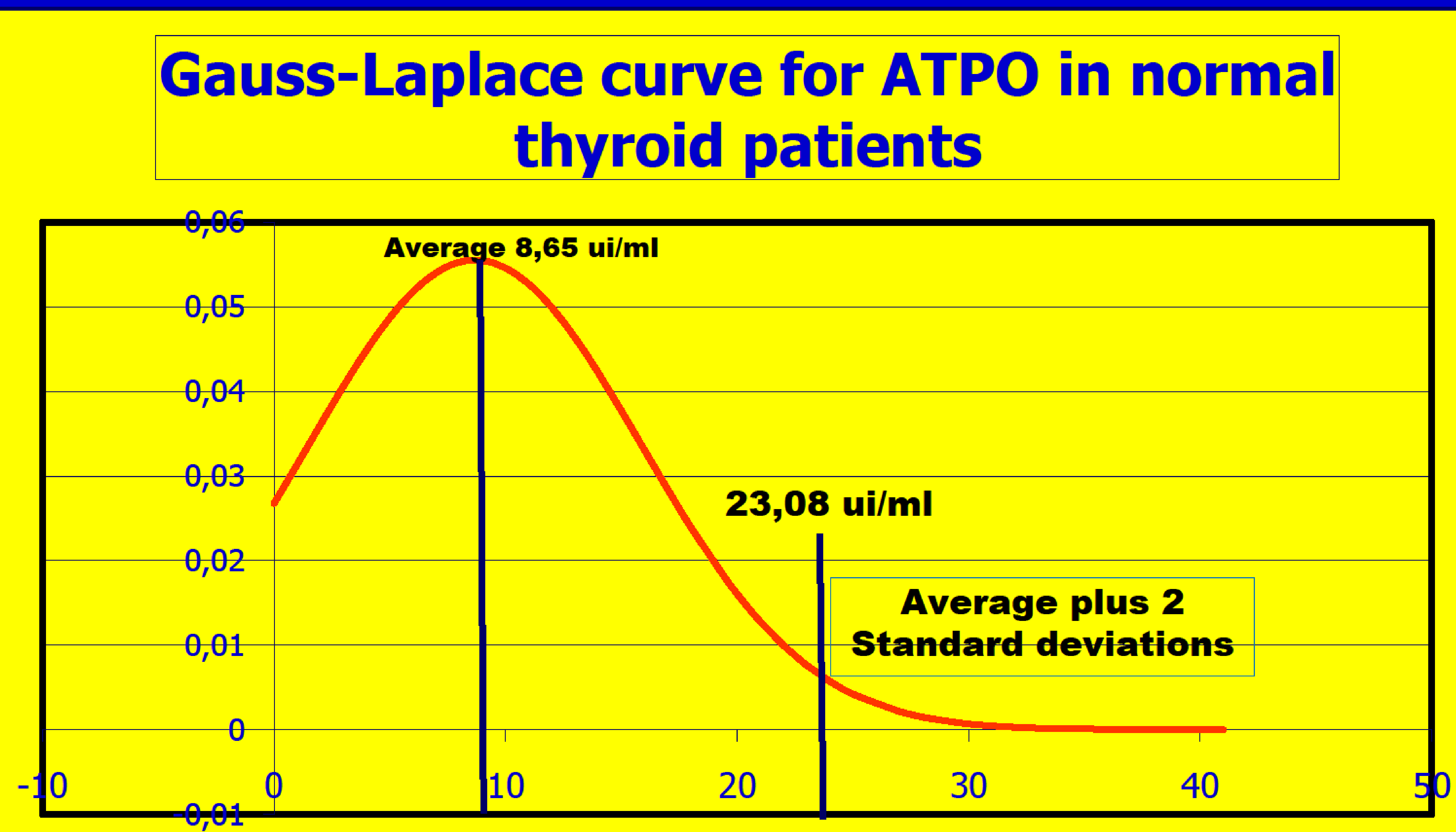

\section{ATPO levels ui/mI}

Based on $34 \mathrm{ui} / \mathrm{ml}$ cut-off limit, we registered 1510 patients with HT (higher ATPO), 129 patients with only high antithyroglobuline thyroiditis (ATG-T)(lower ATPO), and 108 patients with idiopathic myxedema (hypothyroidism, lower ATPO/ATG, and inflammatory ultrasound signs).

Considering ATPO cut-off $23 \mathrm{ui} / \mathrm{ml}, 15$ (11,9\%) ATG-T and $6(4,6 \%)$ myxedema were in fact HT patients.

\section{Conclusions}

1. Using the data from our patients, the cut-off limit for ATPO should be $23 \mathrm{ui} / \mathrm{ml}$ and not $34 \mathrm{ui} / \mathrm{ml}$.

2. Based on $23 \mathrm{ui} / \mathrm{ml}$ cut-off limit, the number of patients with Hashimoto thyroiditis increased by $9,5 \%$. 